\title{
Ferrocene-derived P,N ligands: Synthesis and application in enantioselective catalysis
}

\author{
Timothy Noël ${ }^{\mathrm{a}}$ and Johan Van der Eycken ${ }^{\mathrm{b} *}$ \\ ${ }^{a}$ Micro Flow Chemistry \& Process Technology, Department of Chemical Engineering and Chemistry, Eindhoven University of \\ Technology, Den Dolech 2, 5612 AZ Eindhoven, The Netherlands. \\ ${ }^{b}$ Laboratory for Organic and Bioorganic Synthesis, Department of Organic Chemistry, Ghent University, Krijgslaan 281 (S.4), B-9000,
} Ghent, Belgium.

\footnotetext{
Abstract - Due to their unique steric and electronic properties, air-stability and modular structure, chiral hybrid P,N-ferrocenyl ligands play a prominent role in the field of asymmetric catalysis. This report aims to give a concise introduction to the syntheses of chiral hybrid $\mathrm{P}, \mathrm{N}$-ferrocenyl ligands and presents an overview of their application in enantioselective catalysis. This review is of special interest for chemists working on ligand design and asymmetric catalysis, as well as for the broader organic and inorganic community.
}

\footnotetext{
* a Corresponding author. Tel.: +31-40-247-3623; e-mail: t.noel@tue.nl

*bCorresponding author. Tel.: +32-9-264-44-80; fax: +32-9-264-49-98; e-mail: johan.vandereycken@ UGent.be
} 


\section{Contents}

1. Introduction

2. General synthetic routes

2.1. Synthetic routes towards chiral 1,1'-disubstituted P,N-ferrocenes.

2.2. Synthetic routes towards chiral 1,2-disubstituted P,N-ferrocenes.

3. Catalytic applications

3.1. Enantioselective allylic substitution reactions

3.2. Enantioselective Heck reactions

3.3. Enantioselective hydrogenation reactions

3.4. Enantioselective hydrosilylation reactions

3.5. Enantioselective [3+2] cycloadditions

3.6. Miscellaneous reactions

4. Conclusions 


\section{Introduction}

Since its serendipitous discovery in $1951,{ }^{1}$ research towards ferrocene-containing compounds has received a lot of attention. ${ }^{2}$ The general structure of ferrocene consists of two cyclopentadienyl rings which are bound on opposite sides of a central iron atom in a $\eta^{5}$-fashion. As a result a so called sandwich complex is formed.

For various reasons, hybrid $\mathrm{P}, \mathrm{N}$-ferrocenyl ligands have found widespread use in asymmetric catalysis. First, ferrocenyl phosphanes are extremely stable towards oxidation and therefore are easy to handle. Second, 1,2disubstituted ferrocene ligands can be obtained in two enantiomeric forms (Fig. 1). These enantiomers possess planar chirality and are specified by the stereodescriptors $S_{\mathrm{p}}$ and $R_{\mathrm{p}}$ following the rules introduced by Schlögl. ${ }^{3}$ The substituted cyclopentadienyl ring is monitored from the opposite site of the iron atom. The priority of the substituents is then attributed according to the CahnIngold-Prelog rules. A clockwise or anticlockwise sequence of the groups results in respectively an $R_{\mathrm{p}}$ or $S_{\mathrm{p}}$ configuration. There exists also a second procedure to assign the enantiomers leading to the opposite planar chiral descriptors. ${ }^{4}$ Throughout this review, we will use the first nomenclature. Third, it is also possible to put substituents on two different cyclopentadienyl rings, a so called 1,1'-disubstitution (Fig. 2). In this case, the ligand possesses no planar chirality. However, upon complexation of the ligand with a metal, axial chirality is obtained due to a restricted rotation of the two cyclopentadienyl rings. Fourth, the combination of a soft phosphorous atom and a hard nitrogen atom leads in many cases to very efficient ligands. ${ }^{5}$

Numerous reviews highlighted the synthesis and applications of ferrocene-based ligands in the past. ${ }^{6}$ With this review, we wish to give a focused and up-to-date summary of the synthetic routes towards chiral hybrid $\mathrm{P}, \mathrm{N}$-ferrocenyl ligands and an overview of the applications of these ligands in enantioselective catalysis.

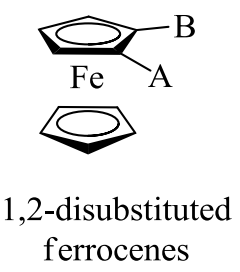

if A $>$ B (counterclockwise rotation): $S_{\mathrm{p}}$ if $\mathrm{A}<\mathrm{B}$ (clockwise rotation): $\quad R_{\mathrm{p}}$

Figure 1. 1,2-Disubstituted ferrocenes possessing planar chirality.

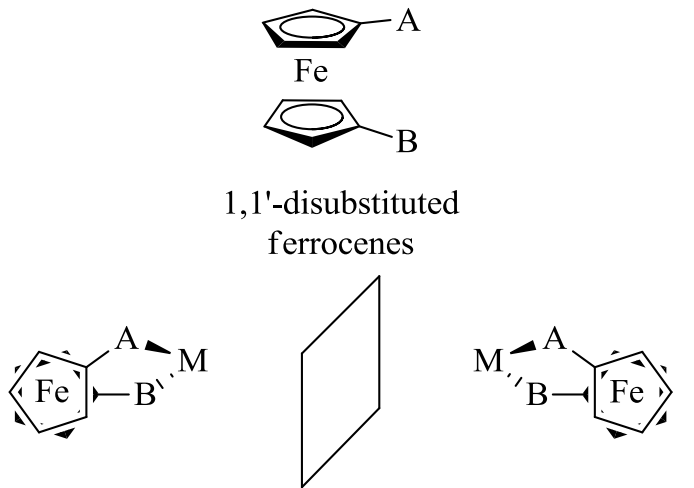

Figure 2. 1,1'-Disubstituted ferrocenes possessing axial chirality upon complexation.

Enantioselective catalysis can be considered as "Green" since it allows to introduce a chiral stereocenter in large amounts of prochiral substrates by utilizing only a limited amount of valuable catalyst. ${ }^{7}$ As such classical stoichiometric methodologies which create a lot of waste are circumvented, e.g. the use of chiral auxiliaries or the separation of two enantiomers via a resolution step.

\section{General synthetic routes}

\subsection{Synthetic routes towards chiral 1,1 '-disubstituted P,N-ferrocenes}

The synthesis of 1,1'-disubstituted P,N-ferrocenyl ligands is less common because it is difficult to avoid both competing 1,2-substitutions and symmetrical substitutions. However, several methods have been developed to obtain these $1,1^{\prime}$ unsymmetrically disubstituted ferrocenes.

The synthesis of chiral 1-oxazolinyl-1'(diphenylphosphino)ferrocenes $\mathbf{5}$ starts from a controlled 1,1 '-dilithiation of ferrocene by $n$-BuLi in the presence of the chelating tetramethylethylenediamine (TMEDA) (Scheme 1). ${ }^{8}$ This product $\mathbf{1}$ is transformed into the corresponding 1,1'-dibromoferrocene $\mathbf{2}$. Via a selective lithium-halogen exchange only one of the two bromines is lithiated and hence differentiation is possible leading eventually to 1-bromo-1'-(2-oxazolinyl)-ferrocene 4 . A second lithium-halogen exchange followed by a reaction with chlorodiphenylphosphane leads to the corresponding chiral hybrid oxazolinyl-ferrocenylphosphane ligand $\mathbf{5}$.

Another specific approach is the ring opening with phenyllithium of the strained 1-phenyl-1-phospha-[1]ferrocenophane $\mathbf{6}$ which can be obtained from the corresponding 1,1'-dilithiated ferrocene 1 (Scheme 2). ${ }^{9}$ When this compound is now reacted with $N, N$ dimethylformamide, the corresponding phosphane ferrocenecarbaldehyde $\mathbf{8}$ is formed. Subsequently, this compound can be condensed with a chiral hydrazine, for example (S)-1-amino-2-(methoxymethyl)-pyrrolidine (SAMP) 9 leading to chiral hybrid phosphane, hydrazone ligand 10. ${ }^{10}$ 
Finally, the use of $\mathrm{N}$-methylpiperazine as a directing group leads to selective lithiation of the 1'-position (Scheme 3). ${ }^{11}$ Hereby, ferrocenecarbaldehyde $\mathbf{1 1}$ is reacted with the lithium salt of $N$-methylpiperazine to give an aminal as a temporary protecting and directing group. Subsequent treatment with $t$-BuLi results in selective lithiation of the 1'-position. A similar directed lithiation 

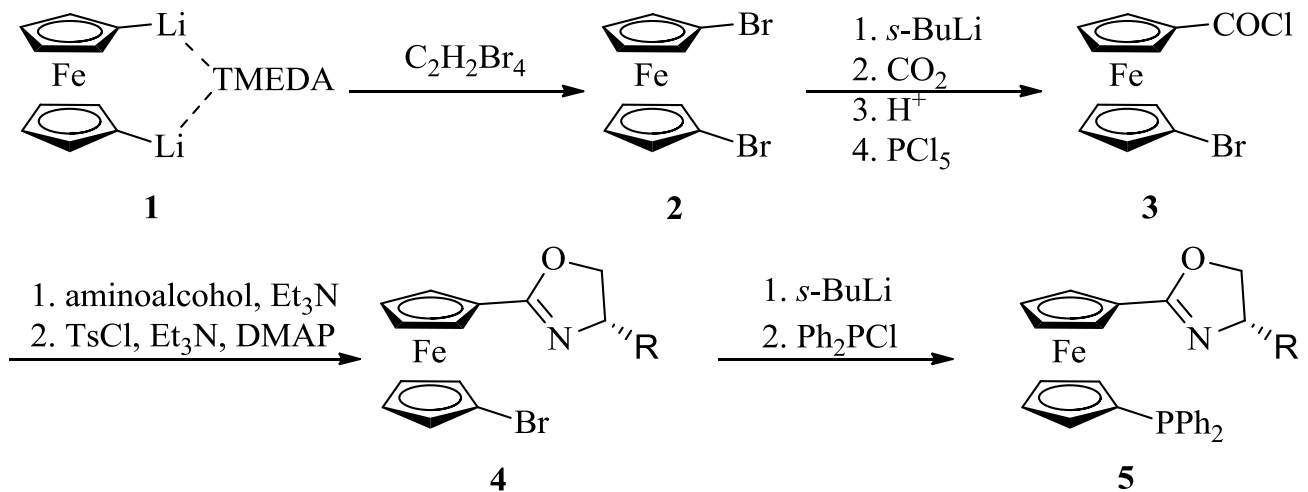

Scheme 1. Synthesis of chiral 1-(2-oxazolinyl)-1'-(diphenylphosphino)ferrocenes 5 via selective lithium-halogen exchange.

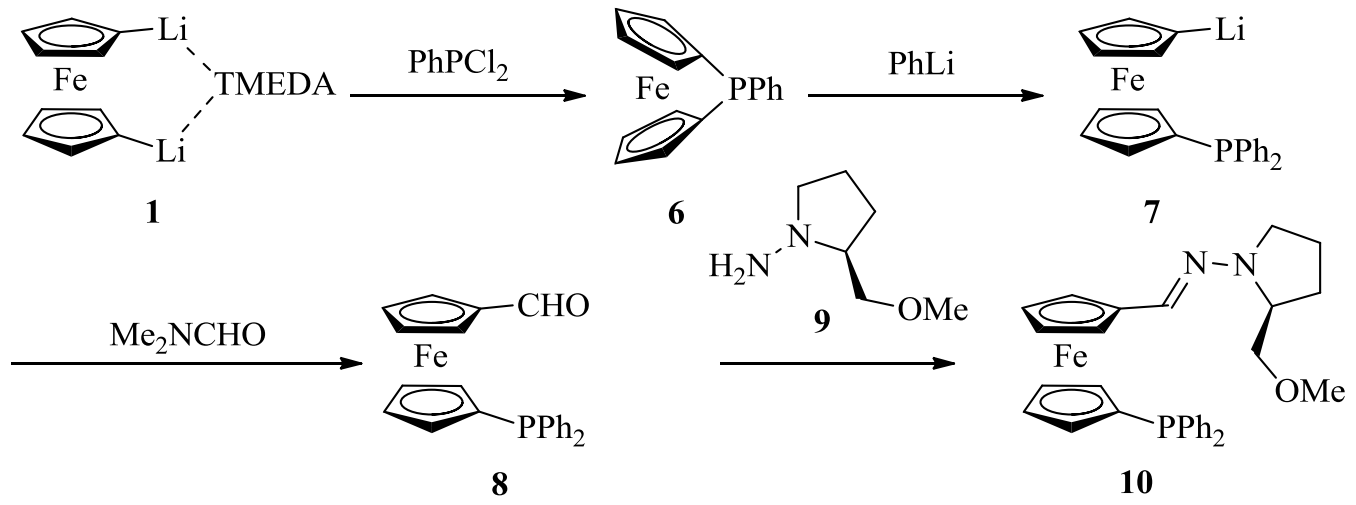

Scheme 2. Synthesis of chiral hybrid phosphane, hydrazone ligand 10 via a ring opening with phenyllithium of the strained 1-phenyl-1-phospha-[1]ferrocenophane 6.
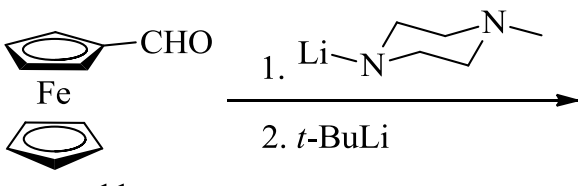

11

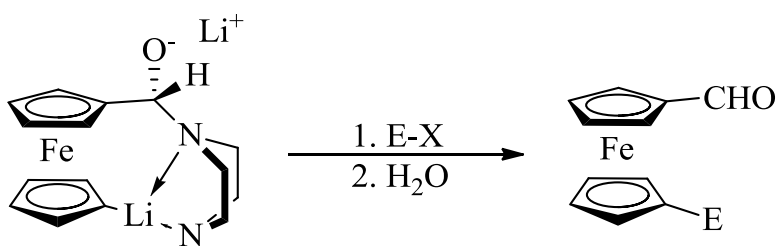

$\mathrm{E}=\mathrm{Me}, \mathrm{Et}, \mathrm{SiMe}_{3}$,

$\mathrm{Bu}_{3} \mathrm{Sn}, \mathrm{BCl}_{3}$,

I, CHO.

Scheme 3. Selective lithiation of the 1'-position.

of the 1'-position has also been observed with a Bocprotected 1-ferrocenylethylamine. ${ }^{12}$

\subsection{Synthetic routes towards chiral 1,2-disubstituted $\mathbf{P}, \mathbf{N}$-ferrocenes}

The preparation of chiral 1,2-disubstituted P,Nferrocenes is typically achieved via diastereoselective ortho-lithiation followed by quenching with an appropriate electrophile. This method was first demonstrated by Ugi with the lithiation of chiral [1-(N,Ndimethylamino)ethyl]ferrocene (12), also called Ugi's amine. ${ }^{13}$ High diastereoselectivity is provided as a result of the sterical repulsion between the methyl substituent and the ferrocene moiety in the unfavored diastereomer (Scheme 4). 

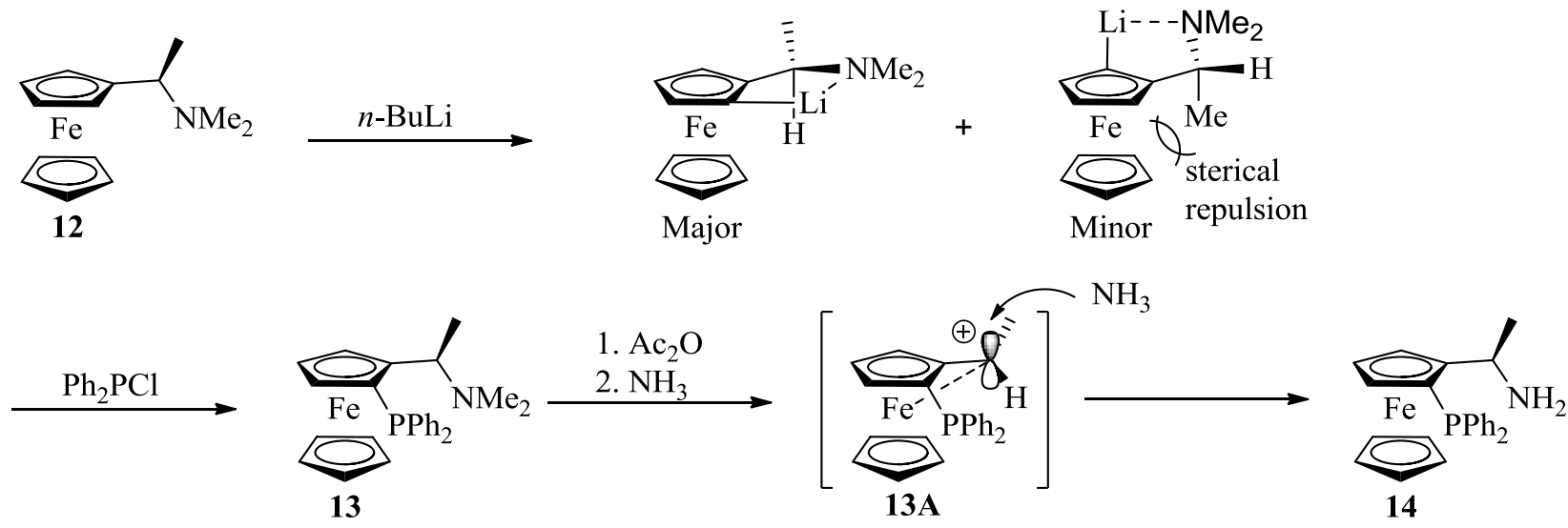

Scheme 4. Synthesis of 1,2-disubstituted P,N-ferrocenes via a diastereoselective ortho-lithiation.

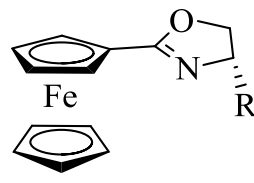

15
1. $n$-BuLi, TMEDA,

$\underset{\text { 2. } \mathrm{TMSCl}}{\stackrel{\mathrm{Et}_{2} \mathrm{O}}{\longrightarrow}}$

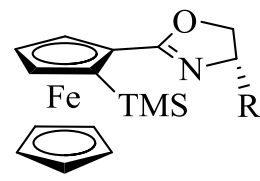

16

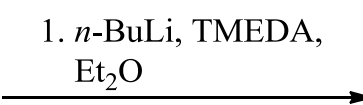

2. $\mathrm{Ph}_{2} \mathrm{PCl}$

3. TBAF

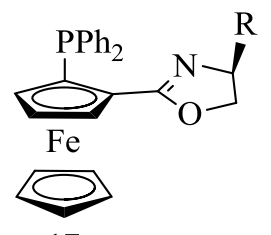

17

Scheme 5. Synthesis of the diastereomer with the opposite planar chirality.

Another remarkable feature is that nucleophilic displacement reactions at the $\alpha$-position proceed with complete retention of configuration. ${ }^{14}$ This is due to the stabilization of the carbenium ion via an overlap with an iron lone pair (13A). Consequently, free rotation around the bond between the ferrocenyl group and the side chain is prohibited, and the nucleophile attacks from the less hindered face. This leads to a conservation of the stereochemistry at the $\alpha$-centre.

Since the original work of Ugi, several other chiral ortho-directing groups have been developed, such as sulfoxides $^{15}$, acetals ${ }^{16}$, sulfoximines ${ }^{17}$, hydrazones ${ }^{18}$, pyrrolidines $^{19}$, imidazolines ${ }^{20}$, azepines ${ }^{21}, \quad O$ methylephedrine derivatives ${ }^{22}$, alcohols ${ }^{23}$, phosphine oxides $^{24}$ and oxazophospholidines. ${ }^{25}$ In addition, oxazolines have been shown by various groups to be excellent ortho-directing groups. ${ }^{26}$ The origin of diastereoselection is shown in Figure 3. Due to steric hindrance from the ferrocene moiety, $n$-BuLi has to approach from the upper side of the ferrocene. This implies that the substituent on the oxazoline moiety has to point downwards in order to avoid sterical repulsion with the incoming $n$-BuLi molecule. Access towards the other diastereomer with opposite planar chirality is provided via introduction of a temporary protecting group followed by lithiation and functionalization of the less favoured position (Scheme 5). ${ }^{25 \mathrm{c}}$
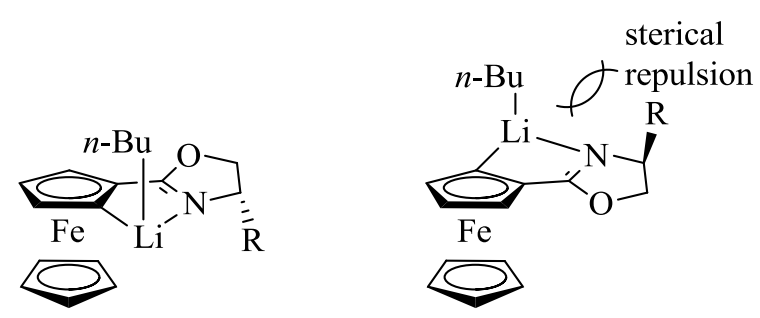

Figure 3. The origin of diastereoselection with an oxazoline as an orthodirecting group.

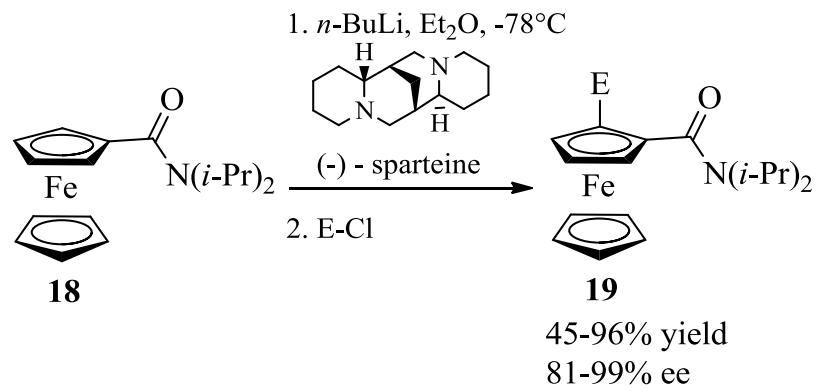

Scheme 6. Enantioselective ortho-lithiation.

In sharp contrast with these chiral ortho-directing groups, the introduction of planar chirality with enantiomerically pure bases is less common. Mostly, low to moderate enantioselectivities were reported. ${ }^{27}$ An interesting exception is the use of an $n$ - $\mathrm{BuLi} /(-)$-sparteine adduct in the ortho-lithiation of ferrocenylamide $\mathbf{1 8}$ 
(Scheme 6). ${ }^{28}$ Excellent enantioselectivities (up to $99 \%$ ee) were obtained.

\section{Catalytic applications}

\subsection{Enantioselective allylic substitution reactions}

The enantioselective allylic substitution reaction has proven to be an excellent reaction for chiral hybrid $\mathrm{P}, \mathrm{N}$ ligands. This can be attributed to the higher trans-effect of the phosphorus as compared to the nitrogen, resulting in an electronic differentiation of the two allylic termini in the transition state complex. It has been shown that the attack of the nucleophile happens at the allylic terminus trans to phosphorus. ${ }^{29}$ It is beyond the scope of this review to cover all chiral hybrid $\mathrm{P}, \mathrm{N}$ ferrocene ligands used in enantioselective allylic substitutions. We will focus our attention on the role of planar chirality in 1,1',2'-substituted and 1,2-disubstituted P,N-ferrocenyl ligands and the influence of the nitrogen donor.

Hou et al. studied the role of planar chirality in 1,1',2'substituted P,N-ferrocenyl ligands (Scheme 7). ${ }^{30}$ Ligand 22 demonstrated high enantioselectivity in the allylic substitution reaction of 1,3-diphenyl-2-propenyl acetate (20) with dimethylmalonate. Introduction of planar chirality into this 1,1'-disubstituted system had a very pronounced effect on the reaction outcome. Remarkably, the presence of this third substituent not only influenced greatly the enantioselectivity but also induced a chirality switch.

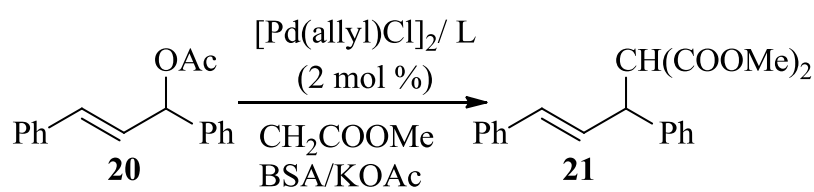

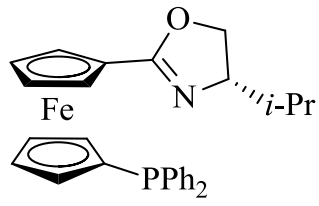

22

$90.8 \%$ ee $(S)$

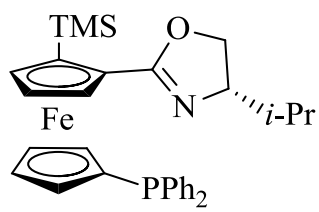

24

$98.6 \%$ ee $(R)$

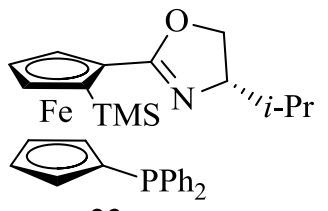

23

$69.7 \%$ ee $(R)$

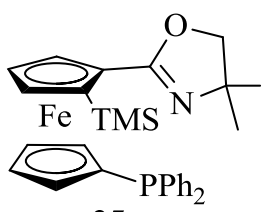

25

$81.9 \%$ ee $(R)$
Scheme 7. The role of planar chirality in $1,1^{\prime}, 2^{\prime}$-substituted P,Nferrocenyl ligands.

Ligands lacking the central chirality on the oxazoline moiety (e.g. 25) still provide good enantioselectivity. This indicates that planar chirality plays a decisive role in the chiral induction. Based on X-ray structures and NMR studies, an explanation for these remarkable results was provided. It was shown that planar chirality influences the ratio of the two rotamers due to sterical interactions (Scheme 8).

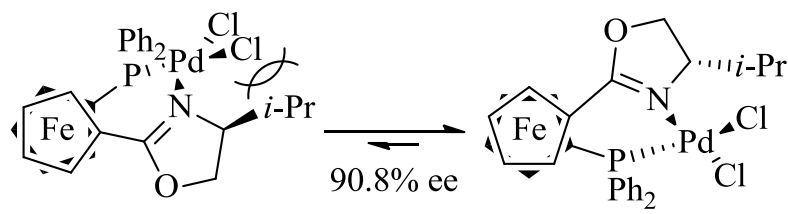

disfavoured

favoured

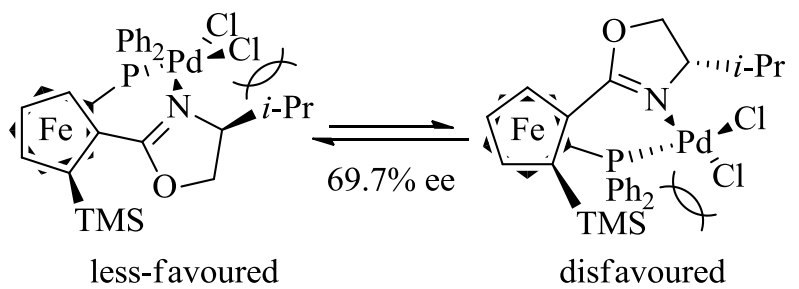

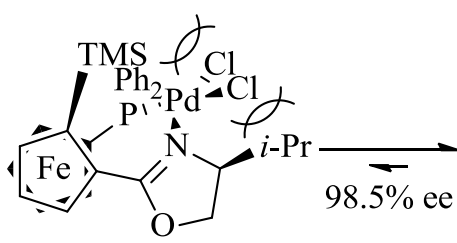

disfavoured

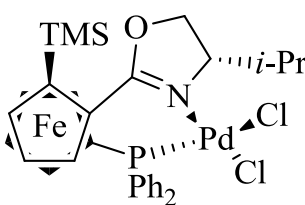

favoured
Scheme 8. Sterical interactions in $1,1^{\prime}, 2^{\prime}$ '-substituted $\mathrm{P}, \mathrm{N}$-ferrocenyl ligands.

The role of planar chirality in 1,2-disubstituted P,Nferrocenyl ligands was studied by Hou et al. ${ }^{31}$ The influence of the planar chirality was less pronounced than in the case of 1,1',2'-substituted ligands as shown in Scheme 9. With ligand 29, lacking the central chirality in the oxazoline moiety, a lower enantioselectivity and a chirality switch were observed. Despite the fact that the central chirality was in this case the most dominant parameter, it was shown that a matching of the central and planar chirality was especially crucial in allylic amination reactions. 


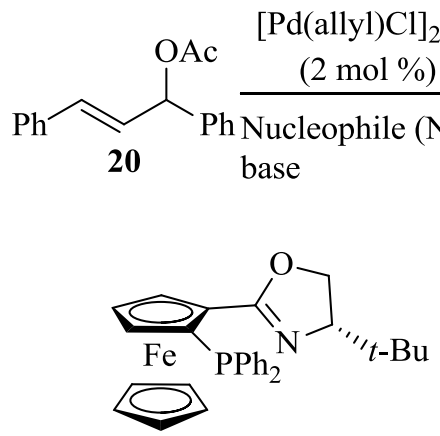

27
21: $\mathrm{NuH}=\mathrm{CH}_{2}(\mathrm{COOMe})_{2}$

26: $\mathrm{NuH}=\mathrm{BnNH}_{2}$

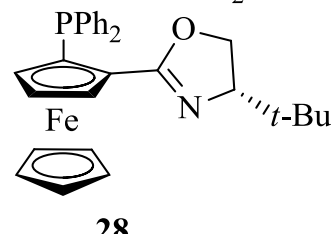

21: $94.6 \%$ ee $(S)$

26: $97.2 \%$ ee $(S)$
26: $91.3 \%$ ee $(S)$

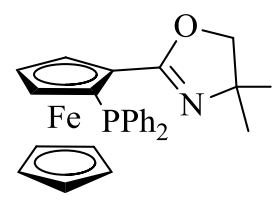

29

21: $54.0 \%$ ee $(R)$

26: $60.3 \%$ ee $(R)$
Recently, Hou et al. reported a method where they use ketone enolates as nucleophiles for the allylic alkylation of cinnamyl tert-butoxycarbonyl carbonate (Scheme 10). ${ }^{32}$ As a result, two chiral centers were constructed in excellent regio-, diastereo- and enantioselectivity. Key for these results was the use of a $1,1^{\prime}$ - substituted P,Nferrocenyl ligand (33) with chirality on the phosphorus.

Noël and Van der Eycken have developed the imidate/phosphane based ferrocenyl ligand $\mathbf{4 2}$ as a new type of P,N-ferrocenyl ligands. ${ }^{33,34}$ These ligands showed very high enantioselectivities in the allylic alkylation of the linear sterically hindered substrate $\mathbf{2 0}$ with a wide variety of carbon nucleophiles (Scheme 11). In addition, good enantioselectivities were obtained in the allylic alkylation of linear sterically unhindered substrate $\mathbf{3 4}$ and cyclic substrates 36-38, demonstrating that this catalyst system has a broad substrate scope. It was also shown that the results depended strongly on the choice of the appropriate $\mathrm{N}, \mathrm{O}$-bis(trimethylsilyl)acetamide (BSA)activator. A comparison with several related nitrogen donor ligands like $\mathbf{4 3}$ and $\mathbf{4 4}$ revealed that the presence of the imidate nitrogen donor ${ }^{35}$ is required for both the high enantioselectivities as the broad substrate scope.

Scheme 9. The role of planar chirality in 1,2-disubstituted P,Nferrocenyl ligands.

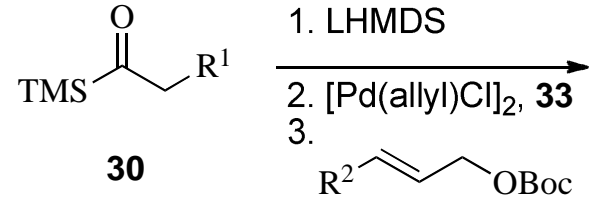

30<smiles></smiles>

31

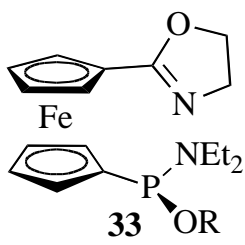

$\mathrm{R}=(R)-1,1$ '-bi-2-naphthol
83\% Yield

$97: 3(31: 32)$

$50: 1 \mathrm{dr}$

99\%ee<smiles>C=C[C@H](Br)[C@H](Br)c1ccccc1</smiles>

92\% Yield

99:1 (31:32)

$10: 1 \mathrm{dr}$

99\%ee 

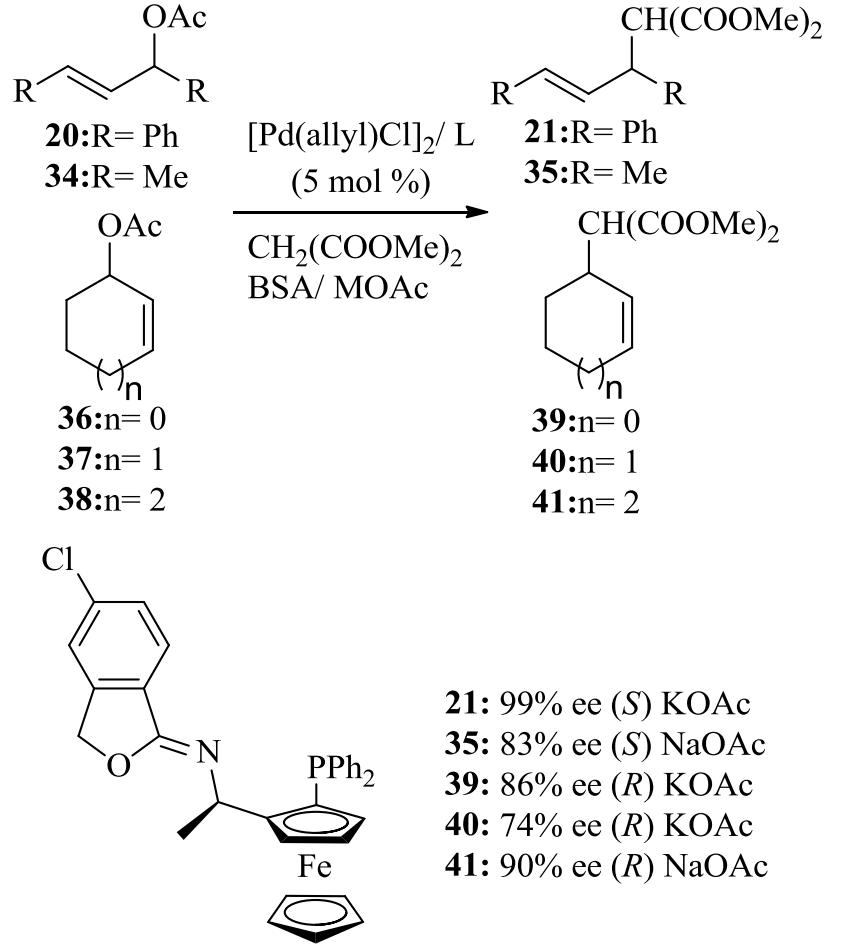

21: $99 \%$ ee $(S)$ KOAc

35: $83 \%$ ee $(S)$ NaOAc

39: $86 \%$ ee $(R)$ KOAc

40: $74 \%$ ee $(R)$ KOAc

41: $90 \%$ ee $(R) \mathrm{NaOAc}$

42

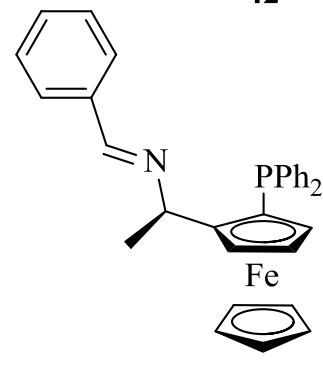

43

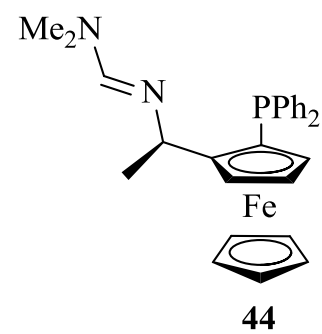

21: $91 \%$ ee $(S)$ KOAc

35: $69 \%$ ee $(S) \mathrm{NaOAc}$

40: $51 \%$ ee $(R)$ KOAc

40: $27 \%$ ee $(R)$ KOAc

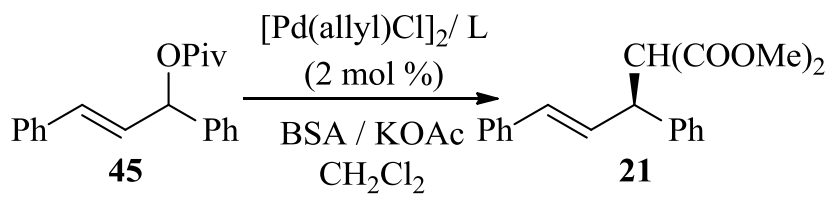

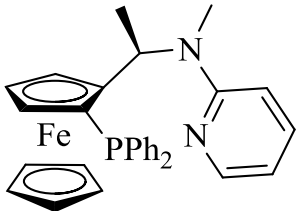

46

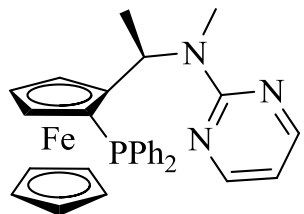

47

$87 \%, 92 \%$ ee
$53 \%, 81 \%$ ee<smiles>COc1nc(OC)nc(N(C)[C@@H](C)c2ccccc2-c2ccccc2)n1</smiles>

48

$99 \%, 98 \%$ ee

Scheme 12. The influence of the heterocyclic moiety on the catalyst performance.

\subsection{Enantioselective Heck reactions}

The Heck reaction is one of the most important C-C bond forming reactions and has been used in the synthesis of several natural products. ${ }^{37}$ Heck reactions can be performed both in an inter- as well as in an intramolecular fashion providing many opportunities for enantioselective catalysis. Design of a ligand that can induce high enantioselectivities in both inter- and intramolecular Heck reaction is a huge challenge.

35: $56 \%$ ee $(S) \mathrm{NaOAc}$

Scheme 11. The use of imidate/phosphane based ferrocenyl ligands in enantioselective allylic alkylation reactions.

Zheng et al. synthesized several ferrocenylphosphanebased heterocyclic ligands and examined the influence of the heterocycle moiety on the catalytic reaction (Scheme 12). ${ }^{36}$ It was shown that the efficiency of the enantioselective allylic alkylation reaction of 1,3-diphenylpropenyl pivalate (45) was strongly dependent on the number of heterocyclic nitrogen atoms. The most efficient ligand (48) contained a triazine moiety.
1,1'-Disubstituted oxazoline, phosphane ligand $\mathbf{5 1}$ was evaluated in the intermolecular enantioselective Heck reaction of dihydrofuran 49 and phenyltriflate (Scheme 13). With these substrates a good enantioselectivity $(76.5 \%$ ee) and reactivity $(80 \%$ yield in $8 \mathrm{~h})$ was obtained. $^{38}$ Introduction of planar chirality led to some remarkable results. The use of ligand $\left(S, S_{\mathrm{p}}\right) \mathbf{- 5 2}$ resulted in a higher selectivity and the opposite stereochemistry. With ligand $\left(S, R_{\mathrm{p}}\right)$-53 an excellent enantioselectivity of $92.1 \%$ ee was obtained. 


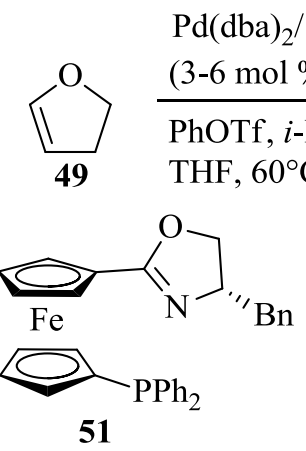

$76.5 \%$ ee $(R)$<smiles>CC(C)[Pb]C1C=CCO1</smiles>

50

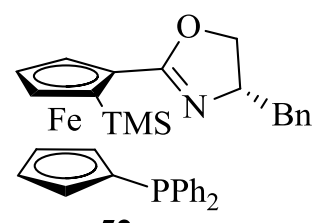

52

$83.5 \%$ ee $(S)$

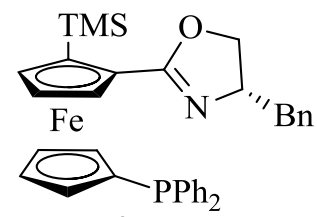

53

$92.1 \%$ ee $(R)$

Scheme 13. The role of planar chirality in the enantioselective Heck reaction with $1,1^{\prime}, 2$ '-substituted $\mathrm{P}, \mathrm{N}$-ferrocenyl ligands.

Guiry et al. investigated 1,2-disubstituted P,Nferrocenyl ligand $\mathbf{2 7}$ in this intermolecular Heck reation of dihydrofuran 49 and phenyltriflate. ${ }^{39}$ Despite the fact that excellent enantioselectivities (up to $99 \%$ ee) were observed, rather poor yields (52\% yield) were obtained even after 14 days of reaction.

Intramolecular Heck reactions have been evaluated too. However, most of the time moderate conversions and enantioselectivities were obtained. ${ }^{40}$

\subsection{Enantioselective hydrogenation reactions}

Catalytic enantioselective hydrogenation reactions of unsaturated compounds are one of the most reliable methods used to synthesize enantiopure compounds. Many research efforts are devoted to development of new and improved hydrogenation catalyst systems. This is due to the fact that for some substrate classes, the development of enantioselective catalyst systems is quite challenging. ${ }^{41}$

Zhou et al. used ligands 27, 28 and $\mathbf{5 6}$ in the iridiumcatalyzed hydrogenation of quinolines (54) and studied the role of planar chirality in this reaction (Scheme 14). ${ }^{42}$ It was shown that the best result was obtained with ligand $\left(S, S_{\mathrm{p}}\right)-\mathbf{2 7}$. With ligand 56, lacking the planar chirality, a significantly lower enantioselectivity was obtained. Since the absolute configuration of the product was in all cases $R$, it can be assumed that the steric course of the reaction is mainly controlled by the central chirality on the oxazoline ring.

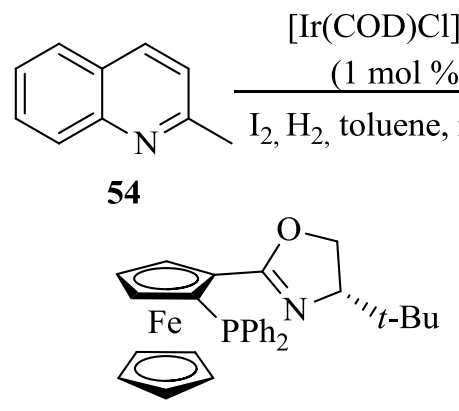

27<smiles>C[C@H]1CCc2ccccc2N1</smiles>

55
$90 \%$ ee $(R)$

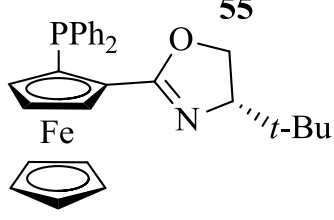

28

$77 \%$ ee $(R)$<smiles>O=S(=O)(c1ccccc1)c1ccccc1C1=N[C@@H](Br)CO1</smiles>

$75 \%$ ee $(R)$

Scheme 14. Enantioselective hydrogenation of 2-methylquinoline.

A small library of imidate/phosphane based ferrocenyl ligands were screened in the iridium(I)-catalyzed hydrogenation of unfunctionalized olefins $\mathbf{5 7} .^{43}$ These substrates are considered as challenging substrates since they do not have a polar coordinating group which can coordinate to the complex to provide high enantioselectivities. ${ }^{44}$ The best results were obtained with ligand 59; up to $99 \%$ for substrate $\mathbf{5 7 b}$. 
<smiles>[R]C([R])=C([R])[R]</smiles><smiles>CC(=Cc1ccccc1)c1ccccc1</smiles>

$57 a$

$1 \mathrm{~mol} \% 59$

50 bar $\mathrm{H}_{2}, 2 \mathrm{~h}$

$99 \%$ yield, $91 \%$ ee $(R)$

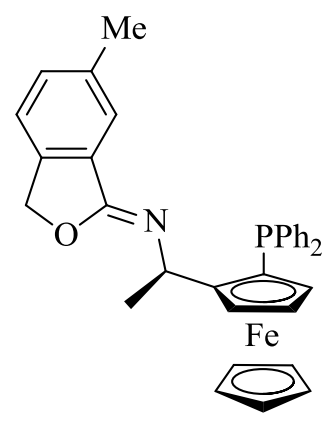

59

Scheme 15. Enantioselective hydrogenation of unfunctionalized olefines.

Ligand $\mathbf{2 7}$ also proved to be effective in the rutheniumcatalyzed hydrogenation of arylketones. High enantioselectivities (up to $99 \%$ ee) were obtained with excellent turnover numbers (TON up to 50,000 ) ${ }^{45}$ In sharp contrast with the catalyst system of Noyori, ${ }^{46}$ these complexes contain no $\mathrm{N}-\mathrm{H}$ group, suggesting a mechanism with a classical $\mathrm{C}=\mathrm{O}$ coordination-insertion of $\mathrm{H}_{2}$.

27 was found to be the ligand of choice in the iridiumcatalyzed enantioselective hydrogenation of $\alpha, \beta$ unsaturated amides furnishing amides with an $\alpha$-chiral center in excellent enantioselectivities (up to $98 \%$ ee). ${ }^{47}$ The authors concluded that the presence of a hydrogen on the amide nitrogen was required for obtaining high selectivities.

Also in ruthenium-catalyzed transfer hydrogenations of aryl ketones, oxazolinyl-ferrocenylphosphane ligands proved to be effective. Enantioselectivities of $>95 \%$ ee were usually obtained using $i-\mathrm{PrOH}$ as a hydrogen donor. ${ }^{48,49}$

\subsection{Enantioselective hydrosilylation reactions}

The rhodium-catalyzed hydrosilylation followed by hydrolysis of the silyl ether is a practical alternative for the enantioselective hydrogenation of ketones. Hayashi et al. reported the use of mixed imino/phosphane ferrocenyl ligands in enantioselective rhodium-catalyzed asymmetric hydrosilylation of ketones with diphenylsilane. ${ }^{50}$ Enantioselectivities of up to $90 \%$ ee were obtained.

Excellent enantioselectivities for this transformation were reported by $\mathrm{Fu}$ et al. using planar chiral ligand $\mathbf{6 2}$ (Scheme 16). ${ }^{51}$ It was shown that the enantioselectivity is highly dependent on the proper choice of the silane. Enantioselectivities up to $98 \%$ ee were obtained with $\mathrm{MesPhSiH}_{2}$ for acetophenone as a model substrate. Several other aryl alkyl ketones and dialkyl ketones were subjected to the enantioselective hydrosilylation and, in almost all cases, enantioselectivities of $>99 \%$ ee were obtained.

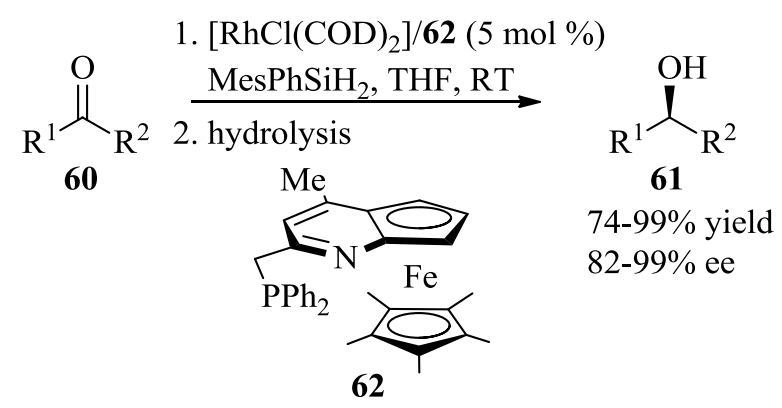

Scheme 16. Enantioselective hydrosilylation of ketones.

\subsection{Enantioselective [3+2] cycloadditions}

1,3-Dipolar cycloadditions are useful reactions for synthesizing five-membered heterocycles. $\mathrm{Fu}$ et al. demonstrated that $\mathrm{P}, \mathrm{N}$-phosphaferrocenyl ligands $\mathbf{6 7}$ and 68 are excellent ligands for the copper-catalyzed [3+2] cycloaddition of azomethine imines $\mathbf{6 3}$ and alkynes (Scheme 17). ${ }^{52}$ Enantioselectivities up to $96 \%$ ee were obtained. Using a ligand with the opposite planar chirality resulted in a significant decrease in ee.

In an extension of this method, it has been shown that the same catalyst system is also effective in the kinetic resolution of racemic azomethine imines rac-65 (Scheme 17). ${ }^{53}$ As a result, a wide variety of enantioenriched 1,3dipoles 65 could be isolated. Subsequent reaction with dipolarophiles provides functionalized pyrazolidinones. 
<smiles>[R]C#CC[N+]1C(=O)CC[N+]1=C[R]</smiles>

$\mathrm{CuI} / 67(5 \mathrm{~mol} \%)$

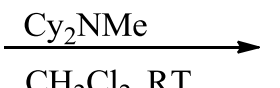

$\mathrm{CH}_{2} \mathrm{Cl}_{2}$, RT

63

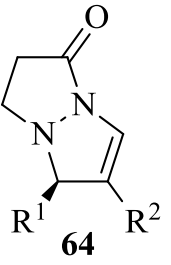

$63-100 \%$ yield

$81-96 \%$ ee<smiles>[R]C(=S)/C=C\C(=O)OCC</smiles>

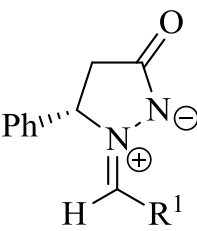

65

$31-48 \%$ yield

$91-99 \%$ ee
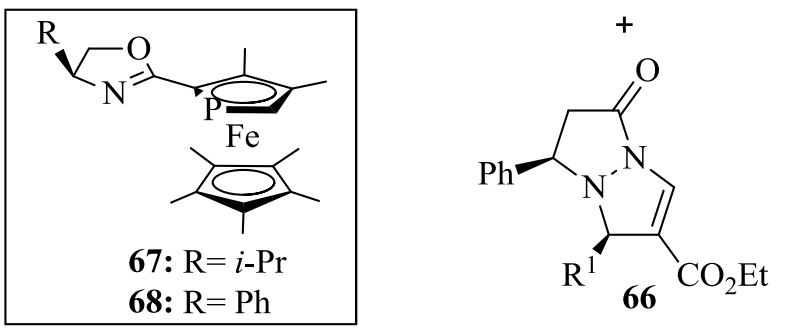

Scheme 17. Cu-catalyzed [3+2] asymmetric cycloadditions of terminal alkynes with azomethine imines.

The $\mathrm{Cu}(\mathrm{I})$-catalyzed reaction of nitrones with terminal alkynes results in the formation of $\beta$-lactams. This reaction is also called the Kinugasa reaction. ${ }^{54}$ The first step involves a 1,3-dipolar cycloaddition with an in situ generated copper(I) acetylide. Hence, a five-membered ring intermediate is formed. Subsequent rearrangement results in the formation of the $\beta$-lactam. Fu et al. developed an enantioselective intramolecular version of this Kinugasa reaction. ${ }^{55}$ With planar chiral phosphaferrocenyl-oxazoline ligands 69 and 70, good to excellent enantioselectivities (85-91\% ee) were obtained (Scheme 18).

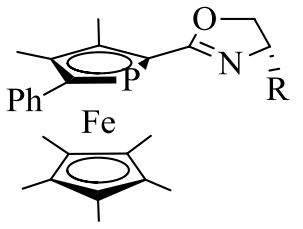

69: $\mathrm{R}=i-\mathrm{Pr}$

70: $\mathrm{R}=t-\mathrm{Bu}$

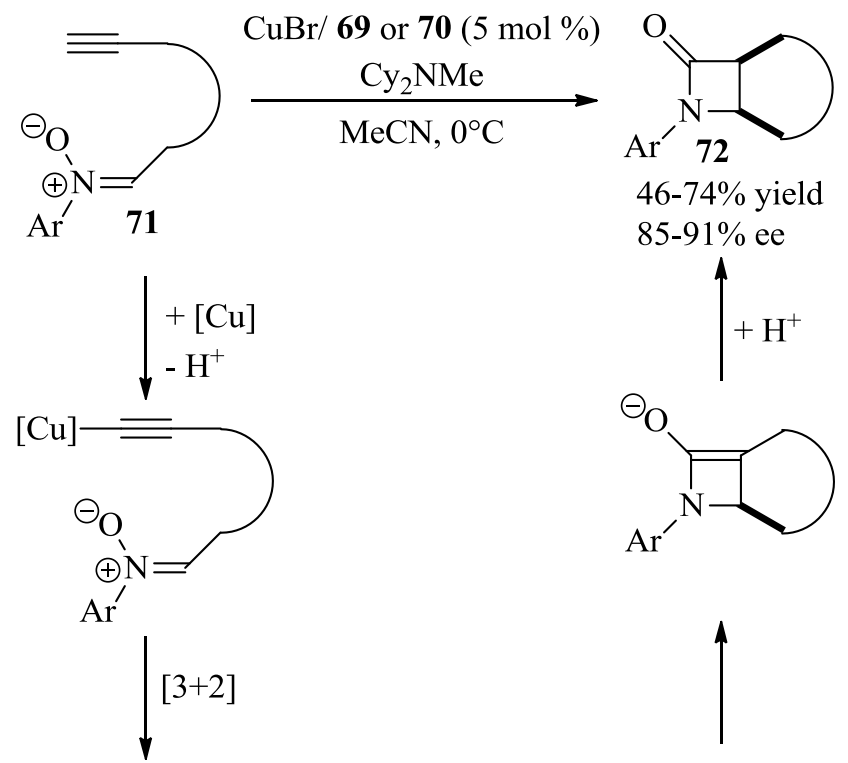

$[\mathrm{Cu}]$<smiles>[AlH2]C1=C2CCCC[C@H]2N([AlH2])O1</smiles><smiles>O=C=C1CC2CCC(C2)C1[Al]</smiles>

Scheme 18. Catalytic enantioselective synthesis of $\beta$-lactams through an intramolecular Kinugasa reaction.

A chiral oxazolinyl-ferrocenylphosphane complex with AgOAc catalyzed the enantioselective cycloaddition of an $\mathrm{N}$-metalated azomethine ylide with electron-deficient alkenes, leading to endo-pyrrolidines in excellent enantioselectivities $(88-98 \%$ ee $){ }^{56}$ Interestingly, when copper(I) complexes of chiral oxazolinylferrocenylphosphane ligands were used, the pyrrolidine products were obtained with a high exo-selectivity and excellent enantioselectivity (84-98\% ee). ${ }^{57}$

Using the same copper source and a similar ligand, Hou et al. developed a 1,3-dipolar cycloaddition of nitroalkenes 73 with $\mathrm{N}$-metalated azomethine ylides derived from $\mathbf{7 4}$ (Scheme 19). ${ }^{58}$ Variations on the nature of the aryl group on the phosphorus atom resulted in a dramatic change of the endo/exo selectivity: electron-rich phosphanes (76) promoted the formation of the exo-adduct as the sole product, while electron poor phosphanes (77) afforded mainly the endo-adduct. 


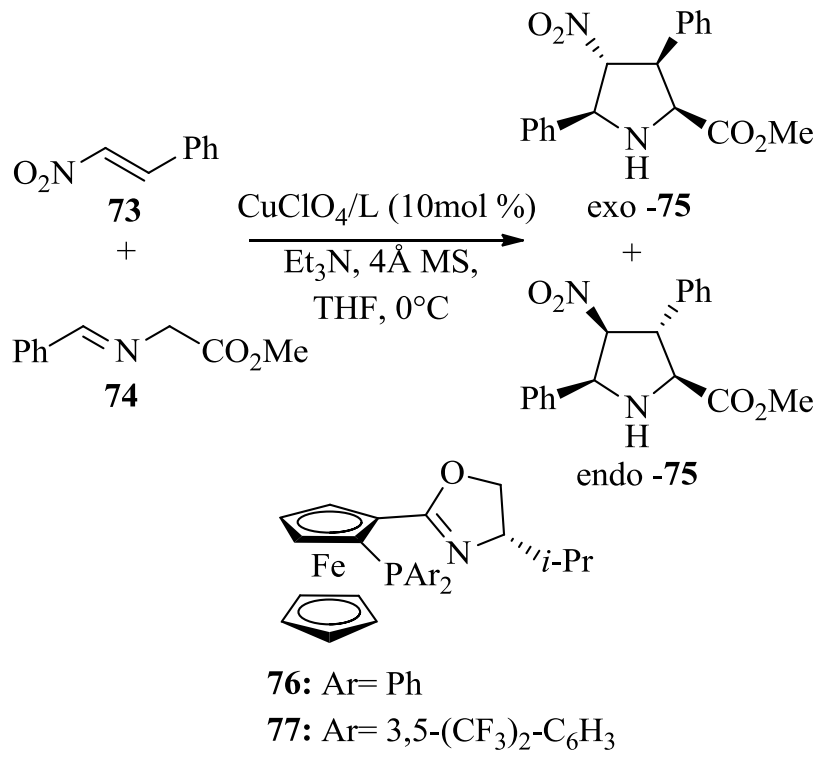

\begin{tabular}{ccccc}
\hline Entry & Ligand & Yield [\%] & exo / endo & $\begin{array}{c}\text { ee [\%] } \\
\text { (exo/endo) }\end{array}$ \\
\hline 1 & $\mathbf{7 6}$ & 58 & only exo & $97 /$ n.d. \\
2 & $\mathbf{7 7}$ & 62 & $18: 82$ & $88 / 97$ \\
\hline
\end{tabular}

Scheme 19. Cu-catalyzed asymmetric 1,3-dipolar cycloaddition of azomethine ylides: influence of the nature of the P-aryl substituent on the phosphorus atom.

\subsection{Miscellaneous reactions}

Schmalz et al. introduced planar chirality in meso(arene)chromium complexes via an enantioselective methoxycarbonylation (Scheme 20). ${ }^{59}$ Although low to moderate yields of $\mathbf{7 9}$ were obtained, the induced enantioselectivity was up to $95 \%$ ee with a chiral pyrrolidinoethyl-ferrocenylphosphane ligand $\mathbf{8 1}$.

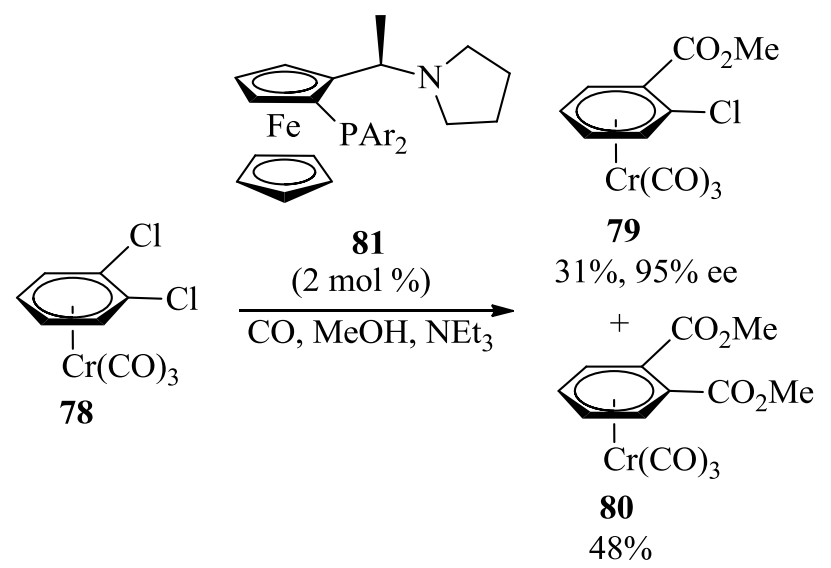

Scheme 20. Introduction of planar chirality via a catalytic enantioselective methoxycarbonylation.
In addition, chiral hybrid $\mathrm{P}, \mathrm{N}$-ferrocenyl ligands also effectively introduce axial chirality. In the presence of $N, N$ dimethyl-1-[2-(diphenylphosphino)ferrocenyl]ethylamine $\left(13\right.$, ppfa) as a ligand, a $C_{2}$-symmetrical binaphthalene was obtained in very good enantioselectivity (up to $85 \%$ ee) via an enantioselective Suzuki cross-coupling. ${ }^{60}$

The $\mathrm{Cu}(\mathrm{OTf})_{2}$-catalyzed addition of diethylzinc to imines in the presence of ppfa $\mathbf{1 3}$ as chiral ligand resulted in good enantioselectivities ( $86-92 \%$ ee). ${ }^{61}$

Togni et al. demonstrated that pyrazolylethylferrocenylphosphane ligands $\mathbf{8 5}$ were effective in rhodiumcatalyzed hydroboration reactions (Scheme 21). ${ }^{62} \mathrm{~A}$ maximum of $95.6 \%$ ee was obtained, albeit with a moderate regioselectivity (branched $\mathbf{8 3}$ /linear 84, 79:21). Similar results were obtained by Knochel et al. with a (2quinolyl)-ferrocenylmethylphosphane ligand. ${ }^{63}$

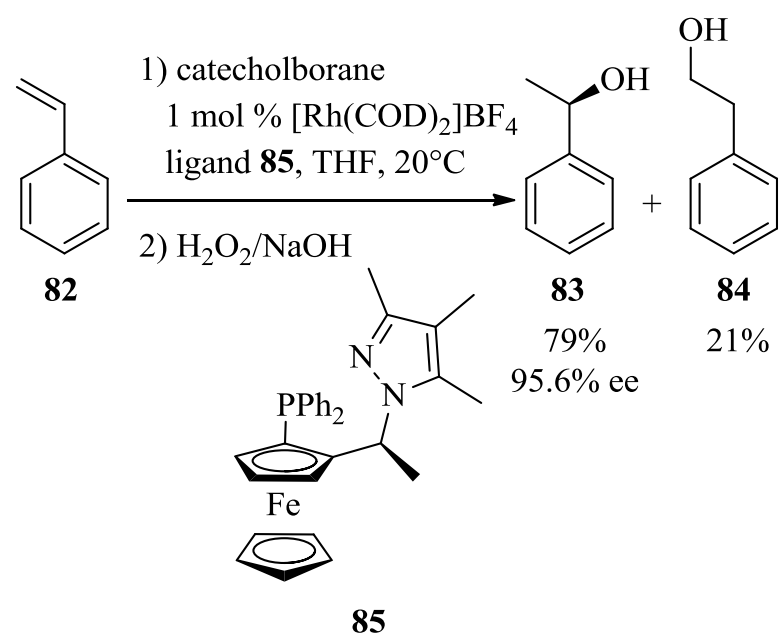

Scheme 21. Catalytic enantioselective hydroboration of styrene with catecholborane.

A chiral oxazolinyl-ferrocenylphosphane ligand (ent76) was used in a nickel-catalyzed enantioselective intramolecular arylcyanation reaction (Scheme 22). ${ }^{64}$ The intermediate product $\mathbf{8 7}$ had an enantioselectivity of $96 \%$ ee and was further used in the synthesis of (-)-esermethole 88.

The same ligand proved to be excellent in a nickelcatalyzed enantioselective annulation reaction of $\mathrm{N}$-aryl1,2,3-benzotriazin-4(3H)-ones 89 with allenes 90 (Scheme 23). ${ }^{65}$ The chiral oxazolinyl-ferrocenylphosphane ligand (76) gave both excellent regio- and enantioselectivities (87$97 \%$ ee). The same catalyst system appeared to be also useful for the enantioselective [2+2+2] cycloaddition of isocyanates and allenes. ${ }^{66}$

\section{Conclusions}

In this review, we have presented an introduction to 
the synthesis of ferrocene-derived $\mathrm{P}, \mathrm{N}$-ligands and compiled a selection of the most important enantioselective transformations in which these ligands were used.

Due to their unique steric and electronic properties, air stability and modular structure, chiral hybrid P,Nferrocenyl ligands have evolved in recent years as exceptional ligands capable of addressing a wide range of enantioselective reactions. We believe that these ligands should be part of each chiral ligand kit for the initial screening of ligands for any new enantioselective reaction. Recently, continuous-flow microreactors have received a significant amount of interest to facilitate rapid screening of chiral catalysts. ${ }^{67}$

Although, a significant amount of research has been done, progress is not without a challenge. At this moment lots of time has been devoted to the synthesis of this valuable ligand class. Due to its modular structure, a rapid diversification of the ligand is possible and, consequently, a lot of $\mathrm{P}, \mathrm{N}$ ligands bearing the ferrocene moiety have been synthesized. This gives the impression that for almost every enantioselective reaction a good ligand is available. In fact, this is not the case. Reactions that generate chiral centers are constantly appearing in the literature, the demand for new and improved chiral catalysts with new reactivities increases. We are convinced that chiral hybrid $\mathrm{P}, \mathrm{N}$-ferrocenyl ligands will play further a central role in the discovery of new enantioselective reactions. 


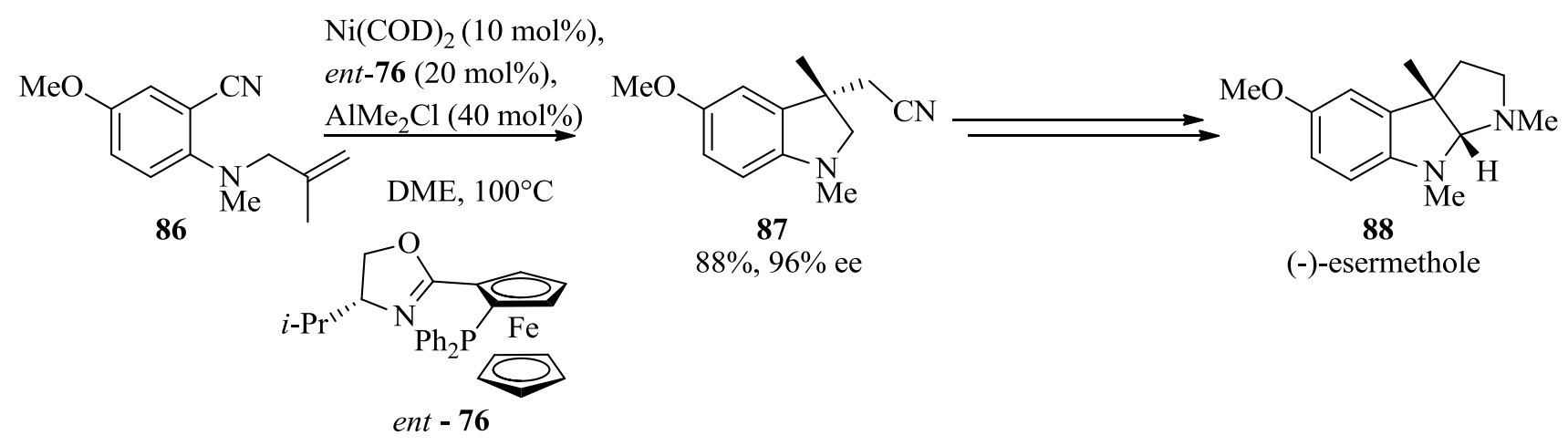

Scheme 22. Catalytic enantioselective intramolecular arylcyanation and its application in the synthesis or (-)-esermethole.

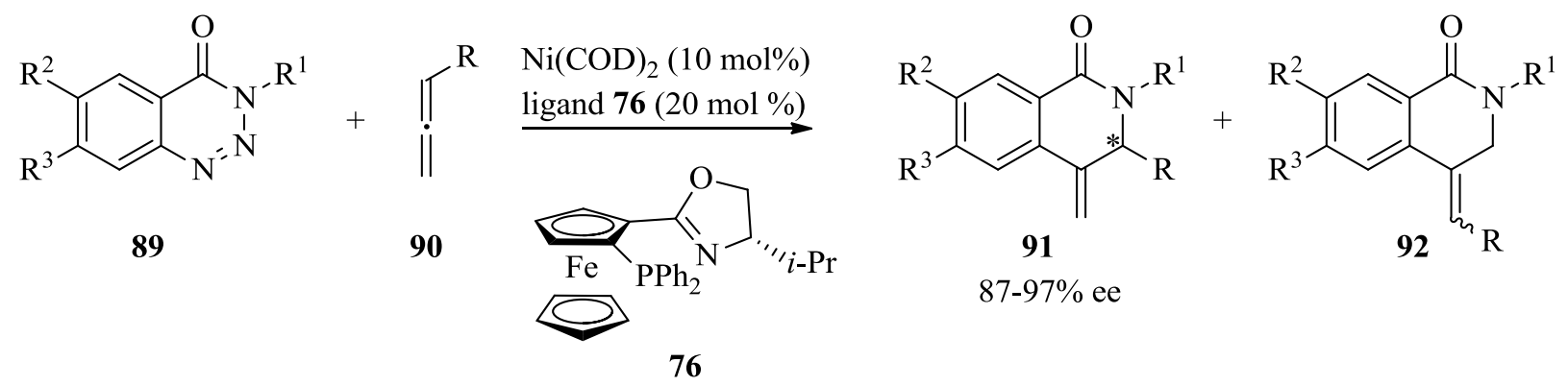

Scheme 23. Catalytic enantioselective annulation reaction of $N$-aryl-1,2,3-benzotriazin-4(3H)-ones $\mathbf{8 9}$ with allenes $\mathbf{9 0}$. 


\section{Acknowledgments}

JVDE wish to thank Ghent University for financial support. TN would like to acknowledge financial support from the Dutch Science Foundation for a VENI Grant $\left(\mathrm{N}^{\circ}\right.$ 12464) and from the European Union for a Marie Curie CIG Grant.

\section{References}

1 For the initial discovery: (a) Kealy, T.J.; Pauson, P.L. Nature 1951, 168, 1039-1040. (b) Miller, S. A.; Tebboth, J.A.; Tremaine, J.F. J. Chem. Soc. 1952, 632-635.

For the determination of the correct structure: (a) Wilkinson, G.; Rosenblum, M.; Whiting, M.C.; Woodward, R.B. J. Am. Chem. Soc. 1952, 74, 2125-2126. (b) Fischer, E.O.; Pfab, W. Z. Naturforsch. B 1952, 7, 377-379.

2 (a) Chiral ferrocenes in asymmetric catalysis: Synthesis and Applications, ed. Dai, L.-X. and Hou, X.-L., Wiley-VCH; Weinheim, 2010, 431 pages. (b) Ferrocenes: Ligands, Materials and Biomolecules, ed. Štěpnička, P., Wiley-VCH; Chichester, England; Hoboken, NJ, 2008, 655 pages. (c) Ferrocenes: Homogeneous catalysis, organic synthesis, materials science, ed. Togni, A. and Hayashi, T., Wiley-VCH; Weinheim, New York, 1995.

3 Bauer, K.; Falk, H.; Schlögl, K. Angew. Chem. Int. Ed. 1969, 8, 135. 4 Schlögl, K. Top. Stereochem. 1967, 1, 39-91.

5 (a) Guiry, P.J.; Saunders, C.P. Adv. Synth. Catal. 2004, 346, 497537. (b) Helmchen, G.; Pfaltz, A. Acc. Chem. Res. 2000, 33, 336345 .

6 For selected examples: (a) Miyake, Y.; Nishibayashi, Y.; Uemura, S. Synlett 2008, 1747-1758. (b) Sutcliffe, O. B.; Bryce, M. R. Tetrahedron: Asymmetry 2003, 14, 2297-2325. (c) Dai, L.-X.; Tu, T.; You, S.-L.; Deng, W.-P.; Hou, X.-L. Acc. Chem. Res. 2003, 36, 659-667. (d) Gomez Arrayas, R.; Adrio, J; Carretero, J.C. Angew. Chem. Int. Ed. Engl. 2006, 45, 7674-7715. (e) Flanagan, S.P.; Guiry, P.J. J. Organomet. Chem. 2006, 691, 2125-2154. (f) Atkinson, R.C.J.; Gibson, V.C.; Long, N.J. Chem. Soc. Rev. 2004, 33, 313-328.

7 (a) Green chemistry and catalysis, ed. Sheldon, R. A.; Arends, I.; Hanefeld, U., Wiley-VCH; Weinheim, 2007, 434 pages. (b) Walsh, P. J.; Li, H.; de Parrodi, C. A., Chem. Rev. 2007, 107, 2503-2545.

8 (a) Park, J.; Quan, Z.; Lee, S.; Ahn, K.H.; Cho, C.-W. J. Organomet. Chem. 1999, 584, 140-146. (b) Butler, I. R.; Davies, R. L. Synthesis 1996, 1350-1354.

9 (a) Štěpnička, P.; Baše, T. Inorg. Chem. Commun. 2001, 4, 682-687. (b) Seyferth, D.; Withers Jr., H.P. J. Organomet. Chem. 1980, 185, C1. (c) Seyferth, D.; Withers Jr., H.P. Organometallics 1982, 1275. (d) Osborne, A.G.; Whiteley, R.H.; Meads, R.E. J. Organomet. Chem. 1980, 193, 345 .

10 Mino, T.; Segawa, H.; Yamashita, M. J. Organomet. Chem. 2004, 689, 2833-2836.

11 Iftime, G.; Moreau-Bossuet, C.; Manoury, E.; Balavoine, G.G.A. Chem. Commun. 1996, 527-528.

12 Chong, J.M.; Hegedus, L.S. Organometallics 2004, 23, 1010-1014.
13 Marquarding, D.; Klusacek, H.; Gokel, G.; Hoffmann, P.; Ugi, I. J. Am. Chem. Soc. 1970, 92, 5389-5393.

14 Gokel, G.W.; Marquarding, D.; Ugi, I.K. J. Org. Chem. 1972, 37, 3052-3058.

15 Rebiere, F.; Riant, O.; Ricard, L.; Kagan, H.B. Angew. Chem. Int. Ed. 1993, 32, 568-570.

16 (a) Riant, O.; Samuel, O.; Flessner, T.; Taudien, S.; Kagan, H.B. J. Org. Chem. 1997, 62, 6733-6745. (b) Riant, O.; Samuel, O.; Kagan, H.B. J. Am. Chem. Soc. 1993, 115, 5835-5836.

17 Bolm, C.; Kesselgruber, M.; Muniz, K.; Raabe, G. Organometallics 2000, 19, 1648-1651.

18 (a) Enders, D.; Peters, R.; Lochtman, R.; Runsink, J. Eur. J. Org. Chem. 2000, 2839-2850. (b) Enders, D.; Peters, R.; Lochtman, R.; Raabe, G. Angew. Chem. Int. Ed. 1999, 38, 2421-2423.

19 Farrell, A.; Goddart, R.; Guiry, P.J. J. Org. Chem. 2002, 67, 42094217.

20 Peters, R.; Fischer, D.F. Org. Lett. 2005, 7, 4137-4140.

21 Widhalm, M.; Mereiter, K.; Bourghida, M. Tetrahedron: Asymmetry 1998, 9, 2983-2986.

22 Xiao, L.; Kitzler, R.; Weissensteiner, W. J. Org. Chem. 2001, 66, 8912-8919.

23 Ueberbacher, B.J.; Griengl, H.; Weber, H. Chem. Commun. 2008, 3287-3289.

24 Nettekoven, U.; Widhalm, M.; Kamer, P.C.J.; Van Leeuwen, P.W.N.M.; Mereiter, K.; Lutz, M.; Spek, A. Organometallics 2000, 19, 2299-2309.

25 Vinci, D.; Mateus, D.; Wu, S.; Hancock, F.; Steiner, A.; Xiao, J. Org. Lett. 2006, 8, 215-218.

26 (a) Sammakia, T.; Latham, H.A.; Schaad, D.R.; J. Org. Chem., 1995, 60, 10-11. (b) Sammakia, T.; Latham, H.A. J. Org. Chem., 1995, 60, 6002-6003. (c) Richards, C.J.; Mulvaney, A.W. Tetrahedron: Asymmetry 1996, 7, 1419-1430. (d) Bolm, C.; Muniz, K.; Seger, A.; Raabe, G.; Günther, K. J. Org. Chem. 1998, 63, 78607867.

27 (a) Price, D.; Simpkins, N.S. Tetrahedron Lett. 1995, 36, 61356136. (b) Nishibayashi, Y.; Arikawa, Y.; Ohe, K.; Uemaru, S. J. Org. Chem. 1996, 61, 1171-1174.

28 Tsukazaki, M.; Tinkl, M.; Roglans, A.; Chapell, B.J.; Taylor, N.J.; Snieckus, V. J. Am. Chem. Soc. 1996, 118, 685-686.

29 (a) Tu, T.; Zhou, Y.G.; Hou, X.-L.; Dai, L-X.; Dong, X.-C.; Yu, Y.H.; Sun, J. Organometallics 2003, 22, 1255-1265. (b) Blöchl, P.E.; Togni, A. Organometallics 1996, 15, 4125-4132.

30 (a) Deng, W.-P.; You, S.-L.; Hou, X.-L.; Dai, L.-X.; Yu, Y.-H.; Xia, W.; Sun, J. J. Am. Chem. Soc. 2001, 123, 6508-6509. (b) Deng, W.P.; Hou, X.-L.; Dai, L.-X.; Yu, Y.-H.; Xia, W. Chem. Commun., 2000, 285-286.

31 You, S.-L.; Hou, X.-L.; Dai, L.-X.; Yu, Y.-H.; Xia, W. J. Org. Chem. 2002, 67, 4684-4695.

32 (a) Chen, J.-P.; Ding, C.-H.; Liu, W.; Hou, X.-L.; Dai, L.-X. J. Am. Chem. Soc. 2010, 132, 15493-15495. (b) Liu, W.; Zhu, X.-Z.; Wan, X.-L.; Hou, X.-L. J. Am. Chem. Soc. 2009, 131, 8734-8735. (c) Zheng, W.-H.; Zheng, B.-H.; Zhang, Y.; Hou, X.-L. J. Am. Chem. Soc. 2007, 129, 7718-7719.

33 Noël, T.; Bert, K.; Van der Eycken, E.; Van der Eycken, J. Eur. J. Org. Chem. 2010, 4056-4061. 
34 For a review of imidate ligands: Noël, T.; Bert, K.; Janssens, P.; Van der Eycken, J. in Innovative Catalysis in Organic Synthesis. Oxidation, Hydrogenation, and C-X Bond Forming Reactions, Ed. P. G. Andersson, Wiley-VCH, Weinheim, Germany, 2012 (ISBN 978-3-527-33097-3).

35 (a) Noël, T.; Vandyck, K.; Robeyns, K.; Van Meervelt, L.; Van der Eycken, J. Tetrahedron 2009, 65, 8879-8884. (b) Noël, T.; Robeyns, K.; Van Meervelt, L.; Van der Eycken, E.; Van der Eycken, J. Tetrahedron: Asymmetry 2009, 20, 1962-1968.

36 Hu, X.-P.; Chen, H.-L.; Zheng, Z. Adv. Synth. Catal. 2005, 347, 541-548.

37 Bräse, S.; de Meijere, A. in Metal-Catalyzed Cross-Coupling Reactions $\left(2^{\text {nd }}\right.$ Edition), ed. A. de Meijere, F. Diederich, WileyVCH, Weinheim, Germany, 2004, 1, 217-315.

38 Deng, W.-P.; Hou, X.-L.; Dai, L.X.; Dong, X.-W. Chem. Commun. 2000, 1483-1484.

39 Kilroy, T.G.; Hennessy, A.J.; Connolly, D.J.; Malone, Y.M.; Farrell, A.; Guiry, P.J. J. Mol. Catal. A: Chem. 2003, 196, 65-81.

40 (a) Kiely, D.; Guiry, P.J. J. Organomet. Chem. 2003, 687, 545-561. (b) Kiely, D.; Guiry, P.J. Tetrahedron Lett. 2003, 44, 7377-7380.

${ }^{41}$ Wills, M. Science 2006, 311, 619-620.

42 Lu, S.-M.; Han, X.W.; Zhou, Y.G. Adv. Synth. Catal. 2004, 346, 909-912.

43 Bert, K.; Noël, T.; Kimpe, W.; Goeman, J. L.; Van der Eycken, J. Org. Biomol. Chem. 2012, 10, 8539-8550.

44 (a) Church, T. L.; Andersson, P. G. Coord. Chem. Rev. 2008, 252, 513-531. (b) Cui, X.; Burgess, K. Chem. Rev. 2005, 105, 32723296.

45 (a) Naud, F.; Malan, C.; Spindler, F.; Rüggeberg, C.; Schmidt, A.T.; Blaser, H.-U. Adv. Synth. Catal. 2006, 348, 47-50. (b) Tellers, D.M.; Bio, M.; Song, Z.J.; McWilliams, J. C.; Sun, Y. Tetrahedron: Asymmetry 2006, 17, 550-553.

46 Noyori, R.; Ohkuma, T. Angew. Chem. Int. Ed. 2001, 40, 40-73.

47 Lu, W.-J.; Hou, X.-L. Adv. Synth. Catal. 2009, 351, 1224-1228.

48 (a) Onodera, G.; Nishibayashi, Y.; Uemura, S. Angew. Chem. Int. Ed. 2006, 45, 3819-3822. (b) Nishibayashi, Y.; Yamauchi, A.; Onodera, G.; Uemura, S. J. Org. Chem. 2003, 68, 5875-5880. (c) Sammakia, T.; Stangeland, E.L. J. Org. Chem. 1997, 62, 6104-6105.

49 (a) Zirakzadeh, A.; Schuecker, R.; Gorgas, N.; Mereiter, K.; Spindler, F.; Weissensteiner, W. Organometallics 2012, 31, 42414250. (b) Schuecker, R.; Zirakzadeh, A.; Mereiter, K.; Spindler, F.; Weissensteiner, W. Organometallics 2011, 30, 4711-4719.

50 Hayashi, T.; Hayashi, C.; Uozumi, Y. Tetrahedron: Asymmetry 1995, 6, 2503-2506.

51 Tao, B.; Fu, G.C. Angew. Chem. Int. Ed. 2002, 41, 3892-3894.

52 Shintani, R.; Fu, G.C. J. Am. Chem. Soc. 2003, 125, 10778-10779.

53 Suárez, A.; Downey, C.W.; Fu, G.C. J. Am. Chem. Soc. 2005, 127, 11244-11245.

54 Kinugasa, M.; Hashimoto, S. Chem. Commun. 1972, 466-467.

55 Shintani, R.; Fu, G.C. Angew. Chem. Int. Ed. 2003, 42, 4082-4085.

56 Zeng, W.; Zhou, Y.-G. Org. Lett. 2005, 7, 5055-5058.

57 Gao, W.; Zhang, X.; Raghunath, M. Org. Lett. 2005, 7, 4241-4244.

58 Yan, X.-X.; Peng, Q.; Zhang, Y.; Zhang, K.; Hong, W.; Hou, X.-L.; Wu, Y.-D. Angew. Chem. Int. Ed. 2006, 45, 1979-1983.

59 (a) Gotov, B.; Schmalz, H.-G. Org. Lett. 2001, 3, 1753-1756. (b) Böttcher, A.; Schmalz, H.-G. Synlett 2003, 1595-1598. (c)
Schumann, H.; Kaufmann, J.; Schmalz, H.-G.; Böttcher, A.; Gotov, B. Synlett 2003, 1783-1788.

60 (a) Cammidge, A.N.; Crépy, K.V.L. Chem. Commun. 2000, 17232724. (b) Cammidge, A.N.; Crépy, K.V.L. Tetrahedron 2004, 60, 4377-4386.

${ }^{61}$ Wang, M.-C.; Liu, L.-T.; Hua, Y.-Z.; Zhang, J.-S.; Shi, Y.-Y.; Wang, D.-K. Tetrahedron: Asymmetry 2005, 16, 2531-2534.

62 Schnyder, A.; Hintermann, L.; Togni, A. Angew. Chem. Int. Ed. 1995, 34, 931-932.

63 Kloetzing, R.J.; Lotz, M.; Knochel, P. Tetrahedron: Asymmetry, 2003, 14, 255-264.

64 (a) Nakao, Y.; Ebata, S.; Yada, A.; Hiyama, T.; Ikawa, M.; Ogoshi, S. J. Am. Chem. Soc. 2008, 130, 12874-12875. (b) Hsieh, J.-C.; Ebata, Y.; Nakao, Y.; Hiyama, T. Synlett 2010, 1709-1711.

65 Yamauchi, M.; Morimoto, M.; Miura, T.; Murakami, M. J. Am. Chem. Soc. 2010, 132, 54-55.

66 Miura, T.; Morimoto, M.; Murakami, M. J. Am. Chem. Soc. 2010 $132,15836-15838$.

67 (a) Zhao, D.; Ding, K. ACS Catalysis 2013, 3, 928-944. (b) Hessel, V.; Kralisch, D.; Kockmann, N.; Noël, T.; Wang, Q. ChemSusChem 2013, 6, 746-789. 